\title{
Expression of Prostate-Specific Antigen Is Transcriptionally Regulated by Genistein in Prostate Cancer Cells
}

\author{
Joanne N. Davis, ${ }^{1}$ Omer Kucuk, ${ }^{2}$ and Fazlul H. Sarkar ${ }^{3 *}$ \\ ${ }^{1}$ Department of Urology, University of Michigan Medical Center, Ann Arbor, Michigan \\ ${ }^{2}$ Department of Internal Medicine, Karmanos Cancer Institute, Wayne State University, Detroit, Michigan \\ ${ }^{3}$ Department of Pathology, Karmanos Cancer Institute, Wayne State University, Detroit, Michigan
}

Prostate cancer is the second-leading cause of cancer-related deaths in men in the United States. Unfortunately, there is no effective therapy when prostate cancer becomes metastatic and refractory to conventional treatments. For this reason, the identification and exploration of new agents that reduce prostate cancer cell growth are of paramount importance. High consumption of plant-derived phytoestrogens is inversely associated with the incidence and mortality rate of prostate cancer. Previous studies, including our own, have shown that the phytoestrogen genistein inhibits prostate cancer cell growth in vitro and in vivo and decreases secreted and intracellular levels of the androgenregulated protein prostate-specific antigen (PSA), but the role of genistein as an agonist/antagonist for hormone receptors remains unclear. To elucidate the mechanism by which genistein modulates PSA protein expression in prostate cancer cells, we investigated the effects of genistein on androgen-mediated and estrogen-mediated transcriptional regulation of PSA, androgen receptor (AR) mRNA and protein expression, and the ability of nuclear proteins to bind to androgen-response elements (AREs) in LNCaP cells. We showed that genistein decreased the transcriptional activation of PSA by both androgen-dependent and androgen-independent methods in LNCaP cells. The reduction of androgen-mediated transcriptional activation of PSA was correlated with decreased AR protein and mRNA levels and decreased binding to AREs. In contrast, genistein had differential effects on 17 $\beta$-estradiol-mediated PSA expressions. Low concentrations of genistein enhanced $17 \beta$-estradiol-mediated PSA expressions, whereas high concentrations of genistein inhibited estrogen-mediated PSA expression in LNCaP cells. Genistein did not inhibit AR protein expression in the presence of $17 \beta$-estradiol. These results suggest that ligand-dependent differences in the ability to activate PSA expression may contribute to the agonistic/antagonistic responses observed with genistein in prostate cancer cells. ๑ 2002 Wiley-Liss, Inc.

Key words: prostate-specific antigen; androgen receptor; gene regulation; genistein

\section{INTRODUCTION}

Prostate cancer is the most common malignancy and the second-leading cause of cancer-related deaths in men in the United States [1]. Androgens and the androgen receptor (AR) play an important role in the development and maintenance of the prostate gland and are involved in prostate tumorigenesis [2]. The $\mathrm{AR}$ is a ligand-specific nuclear transcription factor that binds with high affinity to androgens. The AR transactivates the expression of genes, including prostate-specific antigen (PSA), by binding to androgen-response elements (AREs) located in the promoter [3]. Most prostate cancers are initially androgen dependent, and therefore androgen-ablation therapy leads to tumor regression [4]. Currently, treatments for prostate cancer are based on surgical or chemical castration, which results in decreased circulating androgens and reduces prostate size [5]. Unfortunately, prostate cancer eventually becomes refractory to androgen deprivation and recurs despite continued therapy.
It has been postulated that several molecular mechanisms are responsible for the development of hormone-refractory prostate cancer. A majority of these mechanisms involve alterations in the function of the AR and its signaling pathways. Studies on prostate tissues from human patients have shown that nearly all cancer tissue retains AR expression regardless of clinical stage or hormone responsiveness. One-third of androgen-independent tumors show amplification and overexpression of the $A R$ gene, suggesting that a functional AR pathway favors

*Correspondence to: Department of Pathology, 715 Hudson Webber Cancer Center, 110 E. Warren Detroit, Ml 48202.

Received 20 November 2001; Revised 20 February 2002; Accepted 11 April 2002

Abbreviations: AR, androgen receptor; PSA, prostate-specific antigen; ARE, androgen-response element; DCC, dextran-coated charcoal; ER, estrogen receptor.

DOI 10.1002/mc. 10053 
cell growth [6]. The most frequent $A R$ mutation found in prostate cancer patients is the replacement of threonine 877 with alanine, which corresponds to the mutation seen in the LNCaP prostate cancer cell line [7-9]. This mutation alters the ligand specificity of the receptor such that estrogens, progesterone, adrenal steroids, and anti-androgens can activate the mutant AR, thereby promoting cell growth [10]. Increased expression of $\mathrm{AR}$ has been noted in recurrent hormone-independent tumors [11] and may play a role in the failure of conventional androgen-deprivation therapy in advanced prostate cancer [12]. Therefore, identifying agents that minimize or eliminate AR transactivation may be a useful strategy to prevent and treat prostate cancer.

There is strong epidemiological evidence to suggest that soy isoflavones have a preventative effect against the development of prostate cancer. Chinese and Japanese men, who consume large quantities of isoflavones, have significantly lower prostate cancer incidence and mortality rates $[13,14]$. Genistein, a major soy isoflavone, has been shown to inhibit the cell growth of several types of cancer, including prostate $[15,16]$, breast $[17,18]$, lung [19], and head and neck [20] cancer and leukemia and lymphomas [21]. There are several known biological effects of genistein that may contribute to its antiproliferative effect against cancer. Genistein is a known tyrosine kinase inhibitor [22]; it also inhibits topoisomerase [23] and angiogenesis [24] and induces differentiation in breast cancer cells [25] and apoptosis in prostate cancer cell lines [16]. The exact molecular mechanism by which genistein inhibits tumor cell growth has not been clearly identified, however.

Previous studies, including our own, have shown that the soy isoflavone genistein inhibits prostate cancer cell growth in vitro and in vivo while reducing PSA levels $[26,27]$. PSA, an androgen-responsive gene, produces a protein, which is a known biological tumor marker used to detect and monitor the treatment of prostate cancer patients $[28,29]$. The mechanism by which genistein inhibits PSA protein expression is unknown; for this reason, we investigated the effects of genistein on $A R$ mRNA and protein expression and its functional ability to bind to AREs and ultimately promote androgenmediated PSA gene transactivation. We found that genistein treatment decreased $\mathrm{AR}$ at the mRNA and protein levels, decreased binding of nuclear proteins to AREs, and inhibited PSA gene transactivation in an androgen-dependent and androgenindependent manner. Additionally, we showed that genistein differentially modulated estrogenmediated PSA expression in a dose-dependent manner. Low concentrations of genistein actually enhanced $17 \beta$-estradiol-mediated PSA expression, whereas high concentrations inhibited PSA expression. These results showed the pleiotropic effects of genistein on hormone signaling pathways in prostate cancer cells, suggesting the complexity of AR/PSA regulation in vivo by genistein.

\section{MATERIALS AND METHODS}

\section{Cell Culture}

The human prostate cancer cell line LNCaP was purchased from the American Type Culture Collection (Rockville, MD). LNCaP cells were maintained in RPMI 1640 (GIBCO, Gaithersburg, MD) and supplemented with $5 \%$ fetal calf serum, unless otherwise indicated, with $1 \%$ penicillin/streptomycin at $37^{\circ} \mathrm{C}$ and $5 \% \mathrm{CO}_{2}$.

\section{Cell Treatment}

LNCaP cells were grown to $60-70 \%$ confluence, washed twice with serum-free RPMI 1640 medium, and incubated in medium containing 10\% dextrancoated charcoal (DCC)-stripped serum in the presence or absence of $10^{-10} \mu \mathrm{M}$ R1881 (NEN, Boston, MA) or $1 \mu \mathrm{M} \beta$-estradiol (Sigma, St. Louis, MO). Twenty-four hours later, the cells were treated with either genistein (Toronto Biolabs, Toronto, Canada) or daidzein (BioMol, Plymouth Meeting, PA) at the indicated concentrations for an additional $24 \mathrm{~h}$.

\section{Probe Preparation for Northern Blot Analysis}

A 22-bp oligonucleotide, upper sequence (5'-TCCAGAGCGTGCGCGAAGTGAT-3') and lower sequence (5'-AGCTATCCATCCAGGGGCCCAT-3'), was used for the amplification of an $A R$ cDNA fragment from the total RNA extracted from LNCaP cells following standard methodology. Briefly, $1 \mu \mathrm{g}$ of total RNA was subjected to single-strand cDNA synthesis with the THERMOSCRIPT RT-PCR System (Invitrogen, Carlsbad, CA) and amplified by polymerase chain reaction. Following polymerase chain reaction amplification, the amplicons were separated through an $0.8 \%$ agarose gel and stained with ethidium bromide; the DNA was excised from the gel, purified, and labeled with $\left[\alpha-{ }^{32} \mathrm{P}\right]$ ATP (DuPont NEN, Boston, MA) with the Random Primer Labeling Kit (Stratagene, Cedar Creek, TX). The probe was purified with Stratagene purification columns and used for Northern hybridization.

\section{Northern Blot Analysis}

LNCaP cells were plated on 100-mm dishes and treated with $0,0.5,5$, and $50 \mu \mathrm{M}$ genistein for 12 and $24 \mathrm{~h}$. Total RNA was extracted from each sample with the TRIzol method (Invitrogen, Carlsbad, CA), followed by phenol-chloroform extraction and isopropanol precipitation. Northern gel electrophoresis was performed with $20 \mu \mathrm{g}$ of total RNA per lane in a denaturing gel in $1 \times$ MOPS buffer $(20 \mathrm{mM}$ MOPS, $1 \mathrm{mM}$ EDTA, and $1 \mathrm{mM} \mathrm{NaOAC}$ at $\mathrm{pH}$ 7.0), followed by overnight blot transfer in $10 \times$ standard saline citrate $(1.5 \mathrm{M} \mathrm{NaCl}$ and $0.15 \mathrm{M} \mathrm{Na}$ citrate at $\mathrm{pH}$ 7.0) to a nylon membrane (Hybond $\mathrm{N}+$; 
Amersham Life Sciences, Piscataway, NJ). Hybridization was performed overnight at $65^{\circ} \mathrm{C}$ in $0.25 \mathrm{M}$ $\mathrm{Na}_{2} \mathrm{HPO}_{4}$ and $7 \%$ sodium dodecyl sulfate containing $2 \times 10^{6} \mathrm{cpm} / \mathrm{mL} \alpha-{ }^{32} \mathrm{P}$-labeled $A R$ and a $\beta$-actin probe. The membrane was washed sequentially in $20 \mathrm{mM} \mathrm{Na} \mathrm{HPO}_{4}$ and $5 \%$ sodium dodecyl sulfate, followed by $20 \mathrm{mM} \mathrm{Na}_{2} \mathrm{HPO}_{4}$ and $1 \%$ sodium dodecyl sulfate.

Autoradiographs were obtained by exposing the membrane for $20 \mathrm{~h}$ at $-70^{\circ} \mathrm{C}$. The signal was quantitated for $A R$ mRNA as well as for $\beta$-actin mRNA by scanning the signals with a Gel Doc 1000 image scanner (Bio-Rad, Hercules, CA). The bidimensional optical densities of $A R$ and $\beta$-actin mRNA expression on the films were quantified and analyzed with Molecular Analyst software (Bio-Rad). The ratios of $A R$ mRNA expression against $\beta$-actin were calculated and plotted with GraphPad Prism software (GraphPad Software Inc., San Diego, CA).

\section{Transient Transfection}

LNCaP cells were plated in $35-\mathrm{mm}$ dishes until they reached $60-70 \%$ confluence. Cells were cotransfected with a cytomegalovirus- $\beta$-galactosidase expression vector and pGL3 containing a 6-kb PSA promoter construct in front of a luciferase reporter gene (gift from Dr. Charles Young, Mayo Clinic, Rochester, MN) with Tfx50 (Promega, Madison, WI), following the manufacturer's protocol. Twenty-four hours after transfection, cells were washed with serum-free RPMI medium and reincubated for an additional $24 \mathrm{~h}$ in medium containing either $0.1 \mathrm{nM}$ $\mathrm{R} 1881$ or $1 \mu \mathrm{M} \beta$-estradiol with the indicated concentrations of genistein. Whole-cell extracts were prepared, and the luciferase assay was performed according to the manufacturer's protocol (Promega). The activity of $\beta$-galactosidase was assayed with the manufacturer's protocol (Tropix, Bedford, MA) for normalization of transfection efficiency. Each transfection was performed three times, and standard deviations were calculated and data analyzed with GraphPad Prism statistical software (GraphPad Software Inc.).

\section{Western Blot Analysis}

LNCaP cells were plated in $35-\mathrm{mm}$ dishes and grown to $60-80 \%$ confluence. The cells were washed twice with serum-free RPMI 1640 media and reincubated with media containing $0.1 \mathrm{nM}$ $\mathrm{R} 1881$ or $1 \mu \mathrm{M} \beta$-estradiol. Twenty-four hours later, the cells were treated with the indicated concentrations of genistein or daidzein for an additional $24 \mathrm{~h}$. Whole-cell extracts were harvested, and protein concentrations were determined by BCA protein assay (Bio-Rad). Protein samples were loaded onto either a $6 \%$ or a $12 \%$ acrylamide gel and subjected to gel electrophoresis. Protein samples were transferred to a nitrocellulose membrane. The membranes were blocked for $1 \mathrm{~h}$ in $10 \%$ nonfat dry milk in TBST
(20 mM Tris- $\mathrm{HCl}$ at $\mathrm{pH} 7.6,137 \mathrm{mM} \mathrm{NaCl}$, and $0.1 \%$ Tween 20). The membranes were incubated overnight at $4{ }^{\circ} \mathrm{C}$ in $5 \%$ milk/TBST containing primary antibodies to AR (Neomarkers), PSA (Pharmingen, San Diego, CA), or $\beta$-actin (Bio-Rad). The membranes were washed three times for $10 \mathrm{~min}$ each in TBST and then incubated with anti-mouse horseradish peroxidase secondary antibody (Bio-Rad) for $1 \mathrm{~h}$ at room temperature. The membranes were washed three times for $10 \mathrm{~min}$ each in TBST, and the signal was detected with the chemiluminescence detection system (Pierce, Rockford, IL). Autoradiograms of Western blots were scanned with the Gel Doc 1000 image scanner (Bio-Rad), and the optical density was determined with Molecular Analyst software (Bio-Rad).

\section{Preparation of Nuclear Proteins}

LNCaP cells were plated at a density of $1 \times 10^{6}$ in $100-\mathrm{mm}$ dishes and cultured for $24 \mathrm{~h}$. Subsequently, the cultures were treated with or without genistein for an additional $24 \mathrm{~h}$. Cells were harvested by a cell scraper and washed with phosphate-buffered saline. The cell pellet was resuspended in $0.5 \mathrm{~mL}$ of $10 \mathrm{mM}$ Tris-HCL (pH 7.5), $5 \mathrm{mM} \mathrm{MgCl}_{2}$, and $0.05 \%$ (vol/ vol) Triton X-100 and lysed with 20 strokes with a 1-mL Dounce homogenizer. The homogenate was centrifuged at $1000 \times g$ for $10 \mathrm{~min}$ at $4^{\circ} \mathrm{C}$. The supernatant (cytosolic extract) was collected and frozen at $-70^{\circ} \mathrm{C}$ until further use. The nuclear pellet was treated further for nuclear protein extraction. The pellet volume was estimated and resuspended in an equal volume of $10 \mathrm{mM}$ Tris- $\mathrm{HCl}$ and $5 \mathrm{mM} \mathrm{MgCl}_{2}$, followed by the addition of one nucleus pellet volume of $1 \mathrm{M} \mathrm{NaCl}, 10 \mathrm{mM}$ Tris-HCL (pH 7.5), and $5 \mathrm{mM} \mathrm{MgCl}_{2}$. The lysing nucleus was left on ice for $30 \mathrm{~min}$ and then centrifuged at $10000 \times g$ for $15 \mathrm{~min}$. at $4{ }^{\circ} \mathrm{C}$. The supernatant was removed, and $80 \%$ glycerol was added to a final glycerol concentration of $20 \%$ ( $\mathrm{vol} / \mathrm{vol})$. A BCA protein assay was conducted to determine the protein concentration of each sample.

\section{Labeling of ARE Oligo with $\left[\gamma^{32}\right.$ P]ATP}

The following reagents were assembled for the phosphorylation reaction: $3 \mathrm{pmol}$ of the consensus double-stranded oligonucleotide 5'-AGTTGAGGGGACTTTCCCAGG-3' (ARE) DNA binding sequence obtained from Santa Cruz Biotechnology (Santa Cruz, CA), $5 \times$ T4 polynucleotide kinase buffer, $1 \mathrm{U}$ of T4 polynucleotide kinase, nuclease-free water, and $10 \mu \mathrm{Ci}$ of $\left[\gamma_{-}{ }^{32} \mathrm{P}\right] \mathrm{ATP}$ in a total volume of $10 \mu \mathrm{L}$. The reaction was incubated for $10 \mathrm{~min}$ at $37^{\circ} \mathrm{C}$, and the reaction was stopped with the addition of $0.5 \mathrm{M}$ EDTA. The $\left[\gamma_{-}{ }^{32} \mathrm{P}\right] A T P-l a b e l e d$ ARE consensus sequence was purified with Stratagene Nucprobe (Stratagene, La Jolla, CA). A gel shift assay was performed as previously described [30]. 
RESULTS

Genistein Decreased AR Protein Expression in LNCaP Cells

We previously found that genistein inhibits PSA secretion, protein expression, and mRNA levels in LNCaP cells [26]. PSA is an androgen-responsive gene and is mainly regulated by the AR; for this reason, we examined whether genistein modulates protein expression of the $\mathrm{AR}$, which, in turn, may modulate PSA expression. LNCaP cells were cultured in the absence and presence of $0.1 \mathrm{nM}$ R1881, a nonmetabolized synthetic androgen, and treated with increasing concentrations of genistein. In the absence of androgen, genistein decreased AR protein levels in a dose-dependent manner (Figure 1A). A $25 \%$ reduction in $\mathrm{AR}$ protein expression was observed in LNCaP cells treated with $5 \mu \mathrm{M}$ genistein for $24 \mathrm{~h}$. Cells treated with 30 and $50 \mu \mathrm{M}$ genistein had $70 \%$ and $96 \%$ reductions in AR protein expression, respectively. The inhibitory effect of genistein on AR protein expression was enhanced in the presence of R1881 (Figure 1B). LNCaP cells treated with $0.5 \mu \mathrm{M}$ genistein had a $45 \%$ decrease in AR protein levels, those treated with $1 \mu \mathrm{M}$ genistein had a $80 \%$ reduction, and those treated with $10 \mu \mathrm{M}$ genistein had a $92 \%$ reduction; AR was barely detectable with $50 \mu \mathrm{M}$ genistein. These results showed that genistein reduced AR protein expression in LNCaP cells and that the inhibitory effect of genistein was greater in the presence of androgen.

A
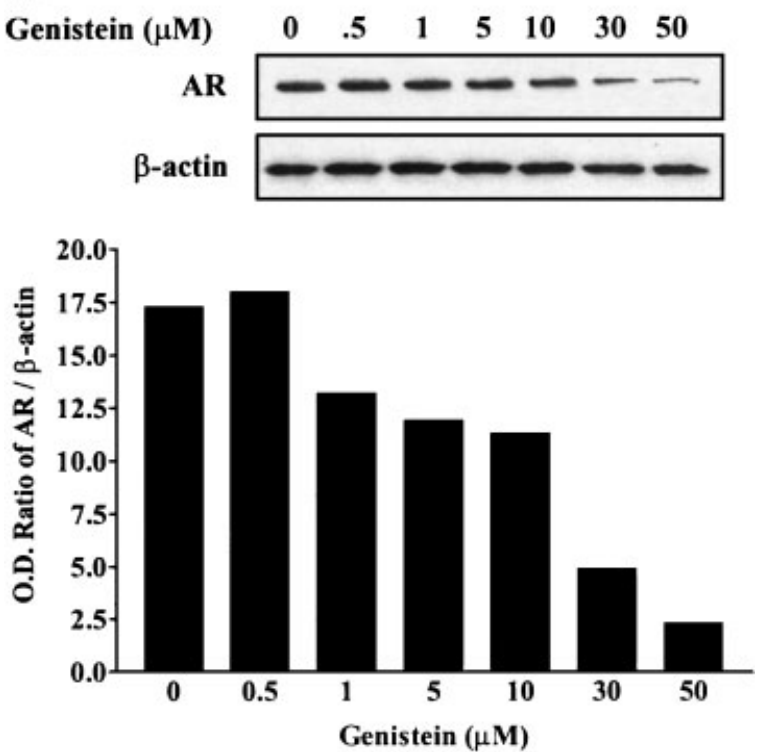

Figure 1. Genistein inhibited AR protein expression levels in LNCaP cells. LNCaP cells were cultured in medium containing DCC stripped serum (A) or supplemented with $0.1 \mathrm{nM} \mathrm{R} 1881$ (B) for $24 \mathrm{~h}$ and subsequently were treated with $0,0.5,1,5,10,30$, and $50 \mu \mathrm{M}$ genistein for an additional $24 \mathrm{~h}$. Whole-cell lysates were harvested,
To determine whether the inhibitory effects of genistein on AR expression were specific, we tested whether daidzein, a compound that is structurally similar to genistein, could inhibit AR and PSA protein expression in $\mathrm{LNCaP}$ cells. Western blot analysis showed that daidzein did not reduce PSA or AR protein levels in LNCaP cells (Figure 2), indicating the specificity of genistein in the downregulation of AR and PSA proteins.

\section{Genistein Inhibited $A R$ mRNA Expression} in LNCaP Cells

To investigate further the modulation of AR by genistein, we conducted Northern blot analysis to detect whether genistein had any effect on $A R$ mRNA levels. LNCaP cells were treated with $0,0.5$, 5 , and $50 \mu \mathrm{M}$ genistein for $12 \mathrm{~h}$ and $24 \mathrm{~h}$, and the total RNA was subjected to Northern blot analysis. We observed a slight reduction of $A R$ mRNA levels in LNCaP cells treated with 0.5 and $5 \mu \mathrm{M}$ genistein within $12 \mathrm{~h}$ of treatment, but there was no similar reduction in the 24 -h treatment group when corrected for gel loading, as measured by the expression of $\beta$-actin mRNA. Nevertheless, a $75-80 \%$ reduction in $A R$ mRNA levels was noted in LNCaP cells treated with $50 \mu \mathrm{M}$ genistein for $12 \mathrm{~h}$ and $24 \mathrm{~h}$ (Figure 3), indicating that high concentrations of genistein inhibited $A R$ mRNA levels. Further in-depth studies, however, are needed to determine whether the stability of the $A R$ mRNA or other factors contribute to the downregulation of $A R$ mRNA in genisteintreated prostate cancer cells.

\section{B}

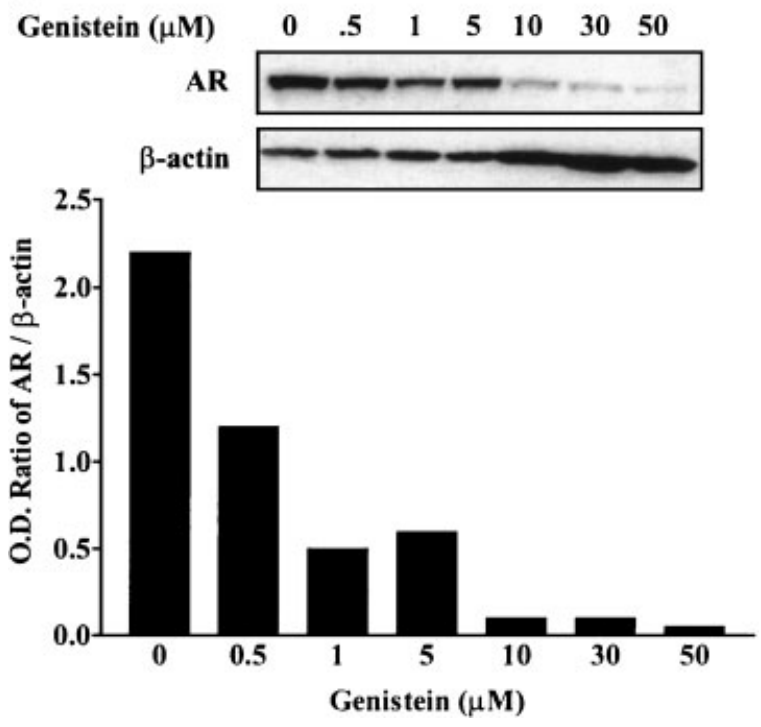

and cell extracts were subjected to Western blot analysis for the detection of $A R$ protein with $\beta$-actin as a loading control. Densitometric analysis was performed for each sample, and the data were plotted as the optical density (O.D.) ratio of AR divided by $\beta$-actin. 


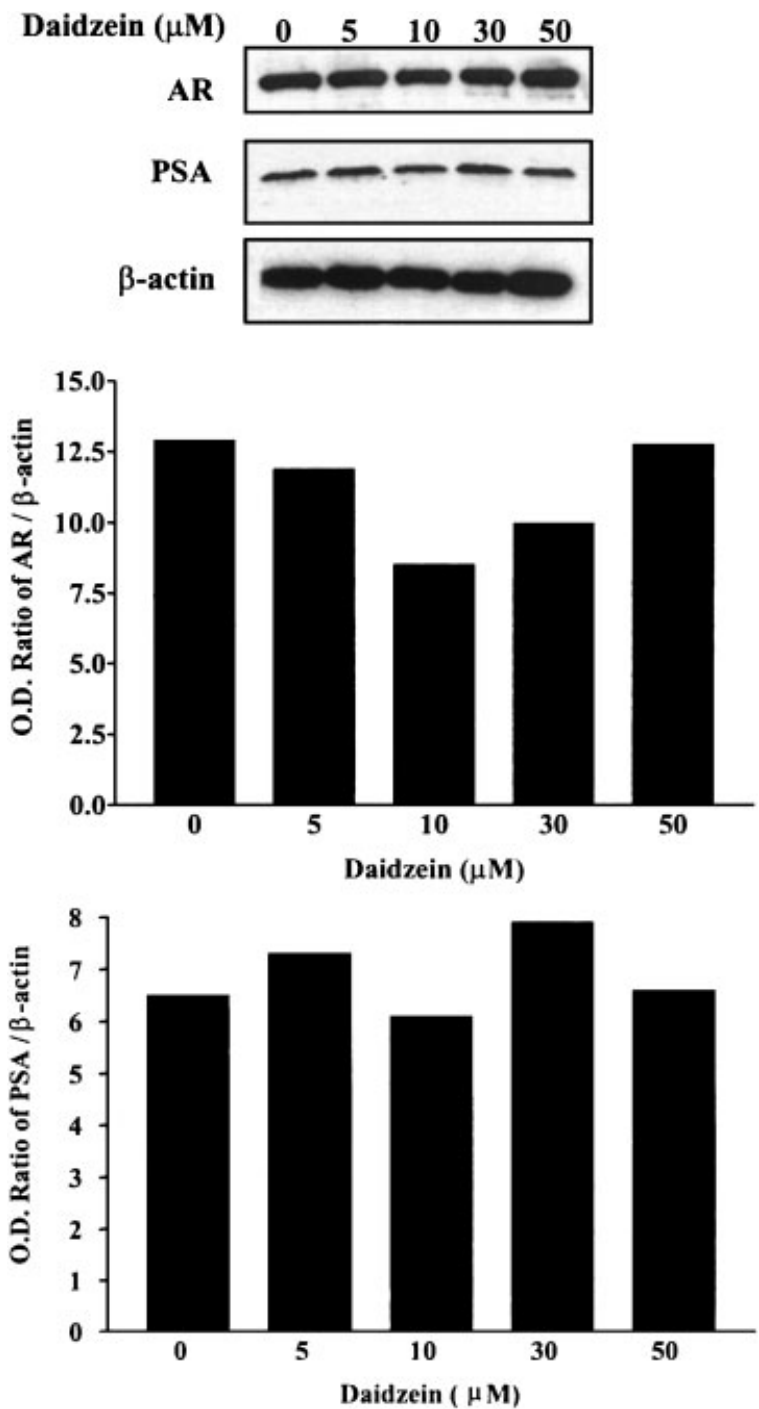

Figure 2. Daidzein did not inhibit PSA or AR protein expression levels. LNCaP cells were treated with $0,5,10,30$, and $50 \mu \mathrm{M}$ daidzein for $24 \mathrm{~h}$. Whole-cell lysates were harvested and subjected to Western blot analysis for the detection of PSA and AR protein, and $\beta$-actin was used as a loading control. O.D., optical density.

Genistein Inhibited Androgen-Mediated and Androgen-Independent PSA Promoter Activity

To assess whether genistein directly affected transcriptional activity of PSA, we transiently transfected LNCaP cells with a 6-kb PSA promoter fragment that contained three AREs in front of a luciferase reporter gene (pPSA-luc). An approximately 160-fold induction of PSA promoter activity was noted in cells incubated in the presence of R1881 (Figure 4A). Androgen-mediated PSA promoter activity was repressed in genistein-treated cells in a dose-dependent manner. Cells treated with $10 \mu \mathrm{M}$ genistein had a $25 \%$ reduction in PSA promoter activity $(P<0.001)$, those treated with $30 \mu \mathrm{M}$ genistein had a $72 \%$ reduction in PSA promoter activity

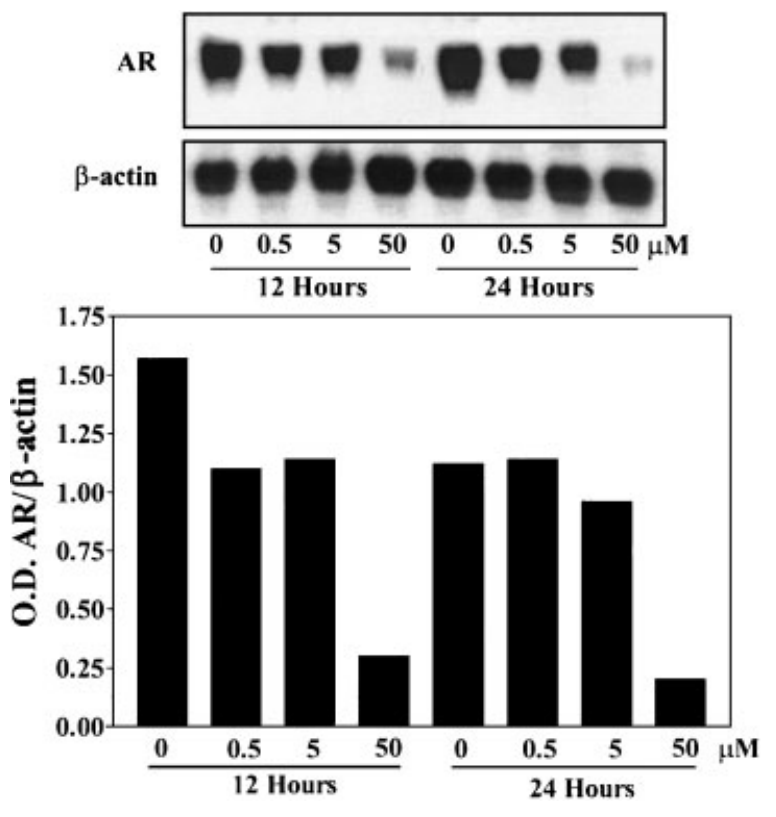

Figure 3. Genistein decreased $A R$ mRNA levels. LNCaP cells were treated with $0,0.5,5$, and $50 \mu \mathrm{M}$ genistein for 12 and $24 \mathrm{~h}$. Total RNA was subjected to Northern blot analysis to detect $A R$ mRNA. Detection of $\beta$-actin mRNA was used as a loading control. Densiometric analysis was performed for each sample, and the data were plotted as the optical density (O.D.) ratio of AR divided by $\beta$-actin.

$(P<0.001)$, and those treated with $50 \mu \mathrm{M}$ genistein had a 93\% reduction in $P S A$ promoter activity $(P<0.001)$ compared with control. To ensure that genistein-mediated inhibition did not reflect toxic or other nonspecific effects of the plasmid or differences in transfection efficiency, luciferase expression in all experiments was normalized with $\beta$ galactosidase production in cells cotransfected with $\beta$-galactosidase control plasmid. The decrease in PSA promoter activity by genistein correlated with the reduction of PSA mRNA levels found in our previous study [26]. These results showed that genistein inhibited androgen-mediated PSA promoter activity in LNCaP cells in a dose-dependent manner.

We have previously shown that high concentrations of genistein inhibits PSA protein expression independent of androgen in $\mathrm{VeCaP}$ cells, a prostate cancer cell line derived from a patient with a hormone-refractory tumor that expresses PSA in an androgen-independent manner [26]. Furthermore, it has been shown that PSA can be transcriptionally regulated in an androgen-independent manner [31-33]. Therefore, we investigated whether genistein inhibited $P S A$ promoter activity in the absence of androgen in LNCaP cells. Minimal PSA promoter activity was observed in LNCaP cells maintained in medium containing 10\% DCC-stripped serum compared with cells treated with R1881 (Figure 4B). Low concentrations of genistein $(1-10 \mu \mathrm{M})$ did not have a significant inhibitory effect on promoter activity, but $30 \mu \mathrm{M}$ genistein decreased the activity by $60 \%$ 
A

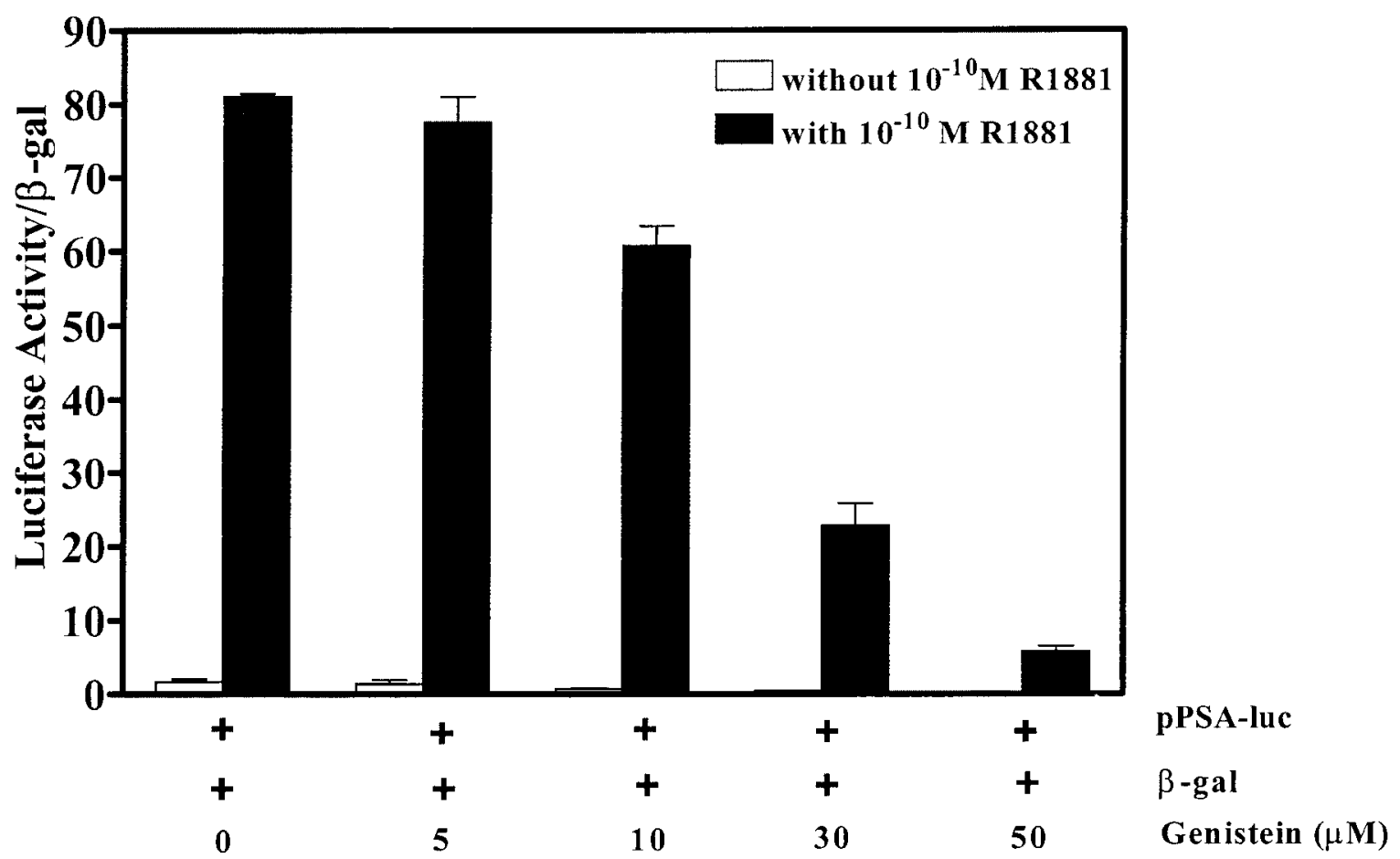

B

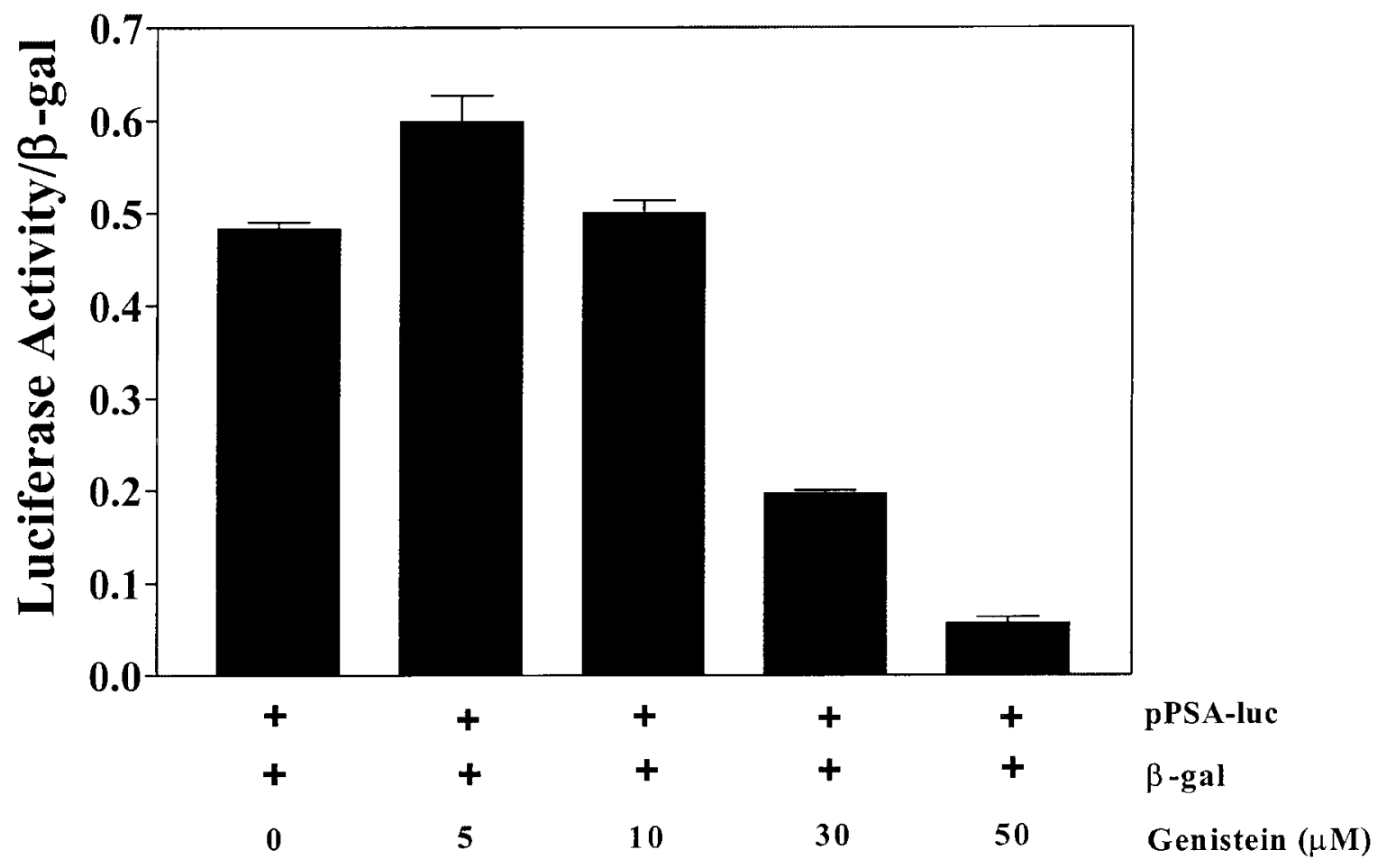

Figure 4. Genistein inhibited androgen-induced PSA promoter activity. (A) LNCaP cells were transfected with a 6-kb PSA promoter fragment containing three AREs in front of a luciferase reporter gene (pPSA-luc). Cells were treated in the presence or absence of $0.1 \mathrm{nM}$ R1881 and subsequently treated with $0,5,10,30$, and $50 \mu \mathrm{M}$ genistein for $24 \mathrm{~h}$. Cell lysates were assayed for luciferase and

$\beta$-galactosidase ( $\beta$-gal). Results are expressed as luciferase relative light units/ $\beta$-galactosidase. (B) LNCaP cells were transfected with pPSA-luc in the absence of androgen and treated with $0,5,10,30$ and $50 \mu \mathrm{M}$ genistein for $24 \mathrm{~h}$ and assayed for luciferase and $\beta$-galactosidase. Results are expressed as luciferase relative light units/ $\beta$-galactosidase. 
$(P<0.001)$ and $50 \mu \mathrm{M}$ genistein by $88 \%(P<0.0001)$ in the absence of exogenous androgen. These results suggested that both androgen-dependent and androgen-independent mechanisms might have been involved in the modulation of PSA signaling pathways by genistein.

Correlation of PSA Expression with the Binding of Nuclear Extracts to the ARE

Transcriptional regulation of PSA by androgens occurs via the ARE in the promoter region of the PSA gene. We examined whether a correlation existed between the binding of nuclear proteins to the ARE in the presence of genistein. LNCaP cells maintained in medium containing R1881 were treated with increasing concentrations of genistein. Nuclear protein extracts were harvested, incubated with a radiolabeled ARE consensus sequence, and subjected to electrophoretic mobility shift assay. Figure 5 shows that the levels of nuclear protein binding to the ARE decreased with increasing concentrations of genistein. Nuclear extracts incubated with excess unlabeled ARE consensus sequence competitively inhibited binding to ${ }^{32}$ P-labeled ARE. Nuclear protein binding to ARE was not detectable in the absence of androgen (data not shown). These results showed that the inhibition of androgen-mediated PSA expression by genistein was due to decreased binding of nuclear proteins to the ARE, which probably resulted in the reduction of $A R$ protein expression.

Genistein Differentially Modulated Estrogen-Mediated PSA Protein Expression in a Dose-Dependent Manner

It has been reported that estrogens bind to and activate AR and regulate PSA expression in LNCaP cells [34]. Genistein is structurally similar to $17 \beta$ -

$\begin{array}{lllllllll}\text { CI } & 0 & .1 & .5 & 1 & 5 & 10 & 50 & \text { Genistein }(\mu M)\end{array}$

AR

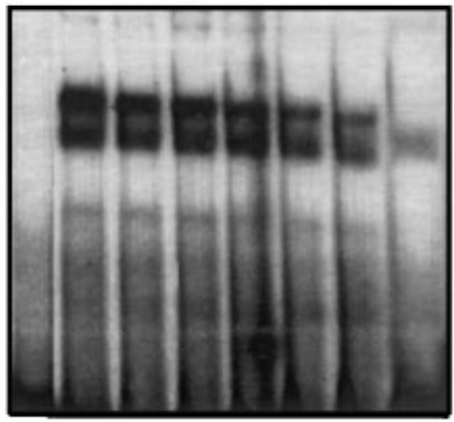

Figure 5. Genistein decreased nuclear protein binding to the ARE in the presence of androgen. LNCaP cells were treated with $0.1 \mathrm{nM}$ $\mathrm{R} 1881$ for $24 \mathrm{~h}$ and subsequently treated with $0,0.1,0.5,1,5,10$, and $50 \mu \mathrm{M}$ genistein for an additional $24 \mathrm{~h}$. Nuclear protein extracts were harvested and incubated with a $\left[\gamma^{32}{ }^{32}\right.$ PATP-labeled $A R E$ consensus oligonucleotide. Samples were subjected to an enzymelinked immunosorbant assay to detect nuclear protein binding. Competitive inhibition (CI) represents nuclear extracts of untreated LNCaP cells incubated with excess unlabeled ARE consensus oligonucleotide.

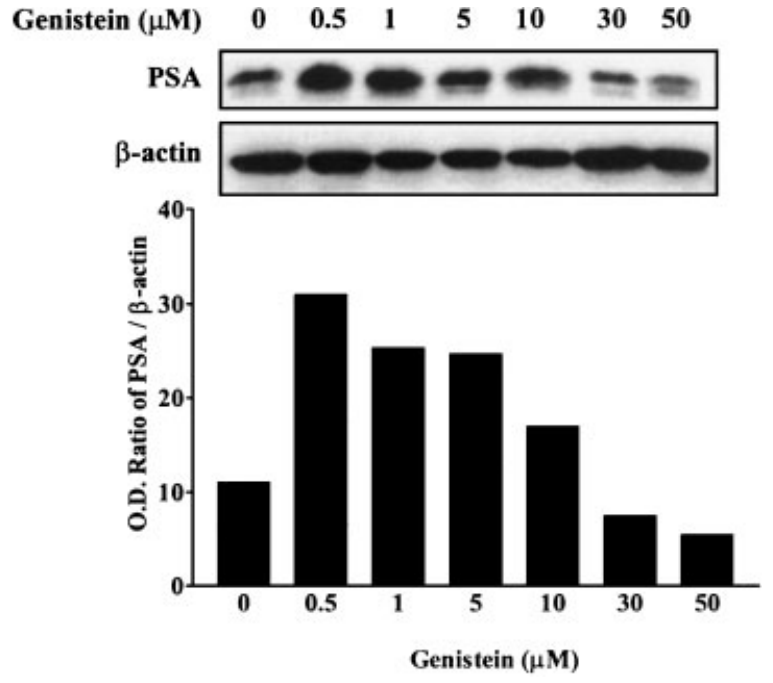

Figure 6. Genistein differentially modulated $\beta$-estradiol-mediated PSA protein expression. LNCaP cells were treated with $1 \mu \mathrm{M}$ $\beta$-estradiol for $24 \mathrm{~h}$ and subsequently treated with $0,0.5,1,5,10$, 30 , and $50 \mu \mathrm{M}$ genistein for an additional $24 \mathrm{~h}$. Whole-cell lysates were harvested and subjected to Western blot analysis for the detection of PSA protein. O.D., optical density.

estradiol and has been reported to have estrogenlike activities by acting as a growth stimulant to estrogen-dependent breast cancer cells $[35,36]$. We observed an increase in PSA protein expression when we treated LNCaP cells with $1 \mu \mathrm{M} 17 \beta$-estradiol (Figure 6). Lower concentrations of $\beta$-estradiol did not significantly affect PSA protein levels. For this reason, we assessed whether genistein modulated PSA expression in the presence of $1 \mu \mathrm{M} 17 \beta$ estradiol in LNCaP cells. When we treated LNCaP cells with genistein in the presence of $\beta$-estradiol, we noted a biphasic response. Low concentrations of genistein $(0.5-5 \mu \mathrm{M})$ enhanced $\beta$-estradiol-induced PSA, but treatment with $10 \mu \mathrm{M}$ or $30 \mu \mathrm{M}$ genistein brought PSA levels back to baseline, and $50 \mu \mathrm{M}$ genistein inhibited PSA protein levels by $30 \%$.

To determine whether the effect of genistein on $\beta$ estradiol-mediated PSA expression occurred at the transcriptional level, we transiently transfected LNCaP cells with the plasmid construct pPSA-luc in the presence and absence of $1 \mu \mathrm{M} \beta$-estradiol. As seen in R1881-treated cells, $\beta$-estradiol-enhanced $P S A$ promoter activity approximately 100 -fold compared with cells maintained in medium containing DCC-stripped serum (Figure 7). Treatment with low concentrations of genistein $(5-10 \mu \mathrm{M})$ slightly enhanced PSA promoter activity, whereas higher concentrations of genistein inhibited activity. These results correlated with the protein levels shown in Figure 6 and demonstrated that the genisteininduced differential effect on $\beta$-estradiol-mediated PSA expression was dose dependent. To understand the mechanism by which genistein modulated $\beta$ estradiol-mediated PSA expression, we conducted Western blot analysis on protein extracts harvested 


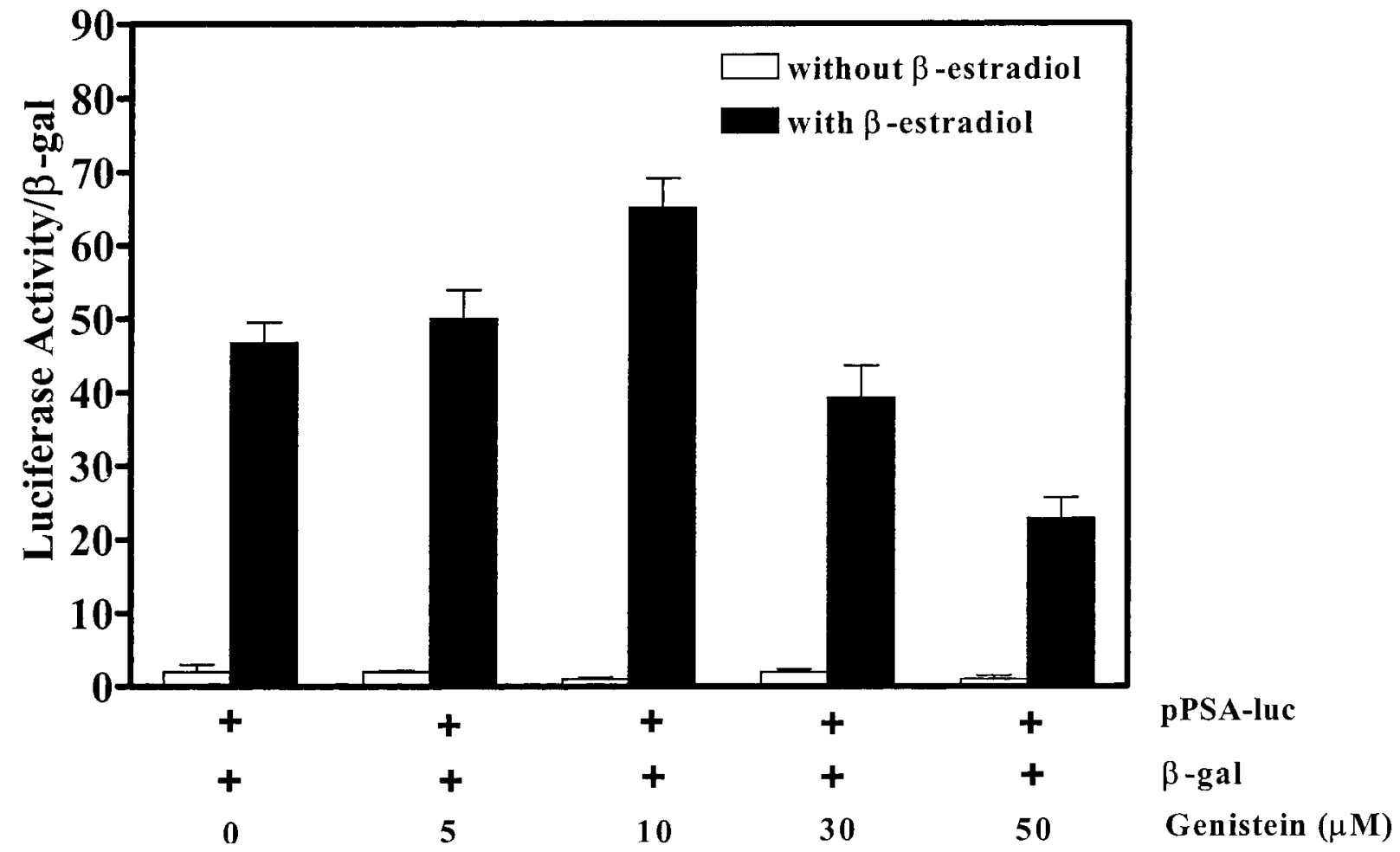

Figure 7. Genistein differentially modulated $\beta$-estradiol-mediated PSA promoter activity. LNCaP cells were transfected with a $6-k b$ PSA promoter fragment containing three AREs in front of a luciferase reporter gene (pPSA-luc). Cells were treated in the presence or

absence of $1 \mu \mathrm{M} \beta$-estradiol and subsequently treated with $0,5,10$ 30 , and $50 \mu \mathrm{M}$ genistein for $24 \mathrm{~h}$. Cell lysates were assayed for luciferase and $\beta$-galactosidase. Results are expressed as luciferase relative light units/ $\beta$-galactosidase.

from LNCaP cells maintained in $1 \mu \mathrm{M} \beta$-estradiol and treated with increasing concentrations of genistein. Figure 8 shows that genistein did not modulate AR protein levels in the presence of $\beta$-estradiol. These results indicated that genistein had multiple and pleiotropic effects on AR and PSA signaling pathways, which may be regulated by the type of ligand present and the functional status of the AR in vivo.

\section{DISCUSSION}

In this report, we describe the inhibition of androgen-dependent and androgen-independent PSA via transcriptional mechanism by the soy isoflavone genistein. This effect was accompanied by decreased AR protein and AR mRNA levels and inhibition of nuclear protein binding to AREs in LNCaP cells. The inhibitory effect of genistein on PSA and AR protein levels was not observed with a structurally similar soy isoflavone, daidzein. Additionally, we have shown that genistein modulated $\beta$-estradiol-induced PSA expression in LNCaP cells in a biphasic manner. Low concentrations of genistein enhanced $\beta$-estradiol-induced PSA protein expression and PSA promoter activity, whereas high concentrations of genistein inhibited $\beta$-estradiolmediated PSA promoter activity and PSA expression. These effects could not be explained by changes in $\mathrm{AR}$ protein levels, demonstrating the diverse and

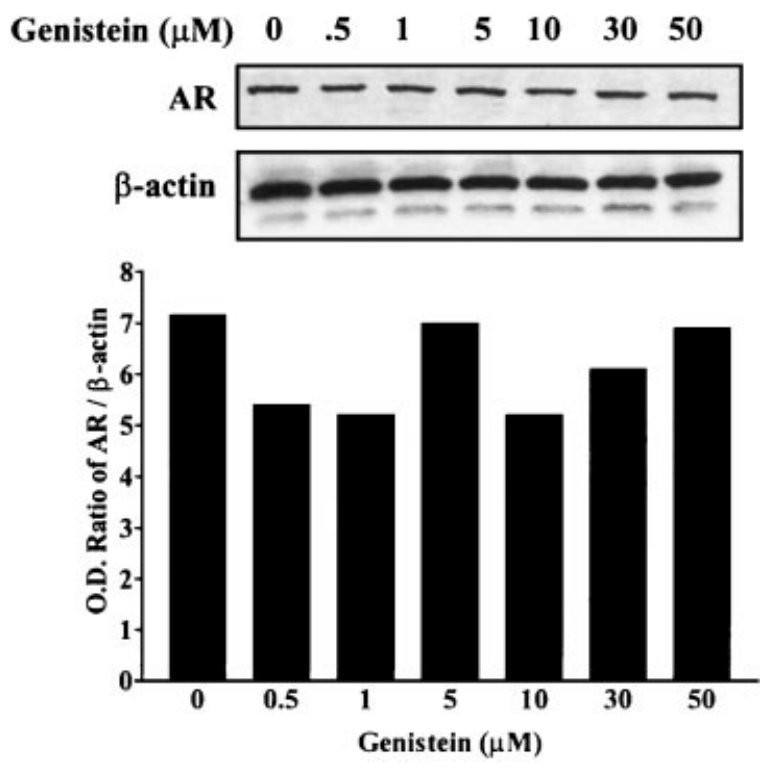

Figure 8 . Genistein did not modulate AR protein expression levels in the presence of $\beta$-estradiol. LNCaP cells were treated with $1 \mu \mathrm{M}$ $\beta$-estradiol for $24 \mathrm{~h}$ and subsequently treated with $0,0.5,1,5,10$, 30 , and $50 \mu \mathrm{M}$ genistein for an additional $24 \mathrm{~h}$. Whole-cell lysates were harvested, and cell extracts were subjected to Western blot analysis for the detection of AR protein. 
pleiotropic effects of genistein on hormone signaling pathways.

The presence of androgen is critical for prostate cancer development. The AR is expressed in prostate cancer cells at all stages of the disease, including androgen-independent metastatic disease [37]. Onethird of androgen-independent tumors show amplification and overexpression of the $A R$ gene, suggesting that a functional AR pathway favors cell growth [6]. The most frequent $A R$ mutation found in prostate cancers is the T877A mutation, which alters ligand binding specificity such that it can bind to and be activated by androgens, estrogens, progesterone, and antiandrogens and contributes to aggressive cell growth [7]. Prostate cancer cells containing mutant receptors, therefore, may have a survival advantage in an androgen-deficient environment. In this study, we showed that genistein could inhibit AR protein and mRNA expression in LNCaP cells in the absence or presence of androgen. Additionally, we showed that the androgen-responsive gene PSA was transcriptionally downregulated by genistein in the absence or presence of androgen. Other researchers and we have shown that genistein treatment decreases prostate cancer cell growth and induces apoptosis in an androgen-independent manner $[14,15,26]$. These results provide evidence to support the role of genistein as a potential therapeutic agent against both androgen-dependent and androgen-independent prostate tumors.

It is well accepted that both androgens and estrogens play a critical role in prostate carcinogenesis. Prostate cancer can be induced in Noble rats by combined treatment with testosterone and $17 \beta$ estradiol $[38,39]$. Testosterone treatment alone produces prostate adenocarcinomas in the dorsal lobe of the prostate in $20 \%$ of Noble rats, but when estrogen is administered simultaneously, prostatic tumors appear more rapidly. The highest incidence of prostate adenocarcinomas has been obtained with prolonged exposure to androgen followed by estrogen, indicating that estrogen plays a critical role in the genesis of prostatic cancers. The precise mechanism by which estrogens promote prostate carcinogenesis is not known. Nevertheless, studies have shown that $\beta$-estradiol increases $A R$ gene transactivation and increases phosphorylation of $A R$ in LNCaP cells [32]. Additionally, PSA was shown to be upregulated by progesterone and estrogen treatment in LNCaP cells [10].

In contrast, exposure to phytoestrogens, particularly soy isoflavones, has been associated inversely with prostate cancer risk and has chemopreventive properties in experimental animal models. In our study, we showed that $\beta$-estradiol increased PSA promoter activity and protein expression. Additionally, we found that genistein had a biphasic dose-dependent response to $\beta$-estradiol-mediated PSA expression. Low concentrations of genistein increased PSA expression, whereas high concentrations were inhibitory. It is conceivable that high levels of genistein may be necessary in vivo for a therapeutic effect, although low concentrations of genistein do not enhance prostate cancer cell growth in vitro. Further studies are required to elucidate the differential effects of genistein on estrogen-mediated and androgen-mediated signaling pathways.

There are several dietary and related compounds that negatively regulate androgen induction of PSA expression in LNCaP cells. Retinoic acid treatment decreases cell proliferation and significantly inhibits PSA expression at the mRNA and protein levels [40]. Treatment with a synthetic retinoid, fenretinide, represses $\mathrm{LNCaP}$ cell proliferation while increasing apoptosis and downregulating PSA protein expression, which is preceded by a reduction of AR protein expression [41]. Biochanin A, a metabolite of genistein, decreases testosterone-stimulated PSA protein expression in LNCaP cells as a result of increased intracellular glucuronidation of testosterone [42]. Another isoflavone, quercetin, has been shown to reduce PSA protein and mRNA levels and lowers AR protein expression [43]. The mechanisms by which these compounds lower PSA and AR levels have not yet been elucidated.

There have been several reports that have examined the interaction of genistein and steroid receptors. Genistein has been shown to bind directly to the estrogen receptor (ER) and modulate its function. It is important to note that prostate cancer cells express ER- $\beta$ more often than ER- $\alpha$, indicating the role of these receptors in prostate cancer. Genistein also can inhibit the transactivating function of the glucocorticoid receptor, possibly owing to inhibition of ligand-induced release of the glucocorticoid receptor from heat shock protein 90 [44]. Reinikainen et al. [45] reported that genistein can suppress androgen induction of an androgen-responsive chloram-phenicol acetyltransferase reporter gene transfected in HeLa cells. In contrast, genistein does not have an effect on androgen-induced activation of wild-type AR in PC3 cells [46]. The inconsistency of these results may be due to different cell types, culture conditions, growth factors, functional status of the $\mathrm{AR}$, and presence of AR co-activators and co-repressors. Recent studies have shown that phytoestrogens have differential effects on the ability of ER- $\alpha$ and ER- $\beta$ to bind co-activator proteins, which result in agonistic/antagonistic responses $[47,48]$.

In our study, we have shown that genistein inhibited androgen-mediated regulation of PSA, but the effects of genistein were dramatically different in the presence of $\beta$-estradiol. The mechanism by which genistein modulates $\beta$-estradiol-induced PSA expression is unknown, but we have shown that these effects were not due to changes in AR 
protein levels. Although it has not been determined whether ER- $\alpha$ and ER- $\beta$, the natural receptors for estrogens, directly regulate PSA expression, they have been identified in prostate cancer specimens and cell lines $[49,50]$. We are currently investigating whether genistein modulates ER- $\alpha$ and ER- $\beta$ functions in LNCaP cells and whether these receptors play a role in the regulation of PSA gene expression. Nevertheless, our data on LNCaP cells directly corroborate the findings reported in a breast cancer cell line, BT474, which was growth stimulated by androgen and produced PSA. On the other hand, growth and PSA production were significantly inhibited by genistein but not by another phytoestrogen, quercetin [51], documenting specific effects of genistein on PSA exactly similar to our results.

In conclusion, our study showed that genistein inhibited androgen-dependent and androgenindependent PSA transactivation, possibly through decreased binding to the ARE and decreased AR protein levels. In addition, low concentrations of genistein enhanced $\beta$-estradiol-mediated PSA regulation, and high concentrations inhibited $\beta$ estradiol-mediated PSA expression. These results indicate the complex role of phytoestrogens in modulating hormone signaling pathways and emphasize the importance of understanding their molecular mechanism of action.

\section{ACKNOWLEDGMENTS}

This work was funded in part by a grant from the National Cancer Institute (CA83695-O1A2 awarded to F.H.S.) and also was supported by an unrestricted grant from the RGK Foundation.

\section{REFERENCES}

1. Greenlee R, Murray T, Bolden S, Wingo P. Cancer statistics, 2000. CA Cancer J Clin 2000;50:7-33.

2. Taplin $E$, Ho S. The endocrinology of prostate cancer J Clin Endocrinol Metab 2001;86:3467-3477.

3. Prins GS. Molecular biology of the androgen receptor. Mayo Clin Proc 2000:75(suppl):S32-S35.

4. Gittes RF. Carcinoma of the prostate. New Engl J Med 1996;324:816-820

5. Huggins C. Two principles in endocrine therapy of cancers: Hormonal deprival and hormonal interference. Cancer Res 1965;25:1163-1167.

6. Visakorpi T, Hyytinen E, Koivisto $P$, et al. In vivo amplification of the androgen receptor gene and progression of human prostate cancer. Nat Genet 1995;9:401-405

7. Taplin M, Bubley G, Shuster $\mathrm{T}$, et al. Mutation of the androgen-receptor gene in metastatic androgen-independent prostate cancer. N Engl J Med 1998;332:1393-1398.

8. Veldschotle J, Ris-Stalpers C, Kuiper G, et al. A mutation in the ligand binding domain of the androgen receptor of human LNCaP cells affects steroid binding characteristics and response to anti-androgens. Biochem Biophys Res Commun 1990;173:534-540.

9. Suzuki H, Akakura K, Komiya A, Aida S, Akimoto S, Shimazaki J. Codon 877 mutation in the androgen receptor gene in advanced prostate cancer: Relation to antiandrogen withdrawal syndrome. Prostate 1996;29:153-158.
10. Montgomery BT, Young C, Bilhartz D, et al. Hormonal regulation of prostate-specific antigen (PSA) glycoprotein in the human prostatic adenocarcinoma cell line, LNCaP. Prostate 1992;21:63-73

11. Latil A, Bieche I, Vidaud D, et al. Evaluation of androgen, estrogen (ER $\alpha$ and $E R \beta$ ), and progesterone receptor expression in human prostate cancer by real time quantitative reverse transcription-polymerase chain reaction assays. Cancer Res 2001:61:1919-1926.

12. Jester $G$. The role of androgen receptor in development and progression of prostate cancer. Semin Oncol 1999;26:407421.

13. Adlercreutz $H$, Honjo $H$, Higashi A. Urinary excretion of lignans and isoflavonoid phytoestrogens in Japanese men and women consuming a traditional Japanese diet. Am J Clin Nutr 1991;54:1093-1100.

14. Adlercreutz H, Goldin B, Gorbach S, Hockerstedt K, Watanabe S. Soybean phytoestrogen intake and cancer risk. J Nutr 1995;125:757S-770S.

15. Peterson TG, Barnes S. Genistein and biochanin A inhibit the growth of human prostate cancer cells in culture but not epidermal growth factor tyrosine phosphorylation. Prostate 1993;22:335-345

16. Davis J, Singh B, Bhuiyan M, Sarkar F. Genistein-induced upregulation of $\mathrm{p} 21^{\mathrm{WAF} 1}$, down-regulation of cyclin $\mathrm{B}$, and induction of apoptosis in prostate cancer cells. Nutr Cancer 1998:32:123-131.

17. Peterson TG, Barnes S. Genistein inhibition of the growth of human breast cancer cells: Independence from estrogen receptors and multi-drug resistance gene product. Biochem Biophys Res Commun 1991;179:661-667

18. Peterson TG, Barnes S. Genistein inhibits both estrogen and growth factor stimulated proliferation of human breast cancer cells. Cell Growth Differ 1996;7:1345-1351.

19. Lian F, Bhuiyan M, Li Y, Wall N, Kraut M, Sarkar F. Genisteininduced G2-M arrest, p21 WAF1 upregulation, and apoptosis in a non-small cell lung cancer cell line. Nutr Cancer 1998; 31:184-191.

20. Alhasan S, Ensley J, Sarkar F. Genistein induced molecular changes in a squamous cell carcinoma of the head and neck cell line. Int J Oncol 2000;16:333-338.

21. Spinnozi F, Pagliacci M, Migliorati G, Moraca R, Grignani F. The natural tyrosine kinase inhibitor genistein produces cel cycle arrest and apoptosis in Jurkat T leukemia cells. Leuk Res 1994:18:431-439.

22. Akiyama T, Ishida J, Nakagawa S, et al. Genistein, a specific inhibitor of tyrosine-specific protein kinase. J Biol Chem 1987:262:5592-5595.

23. Okura A, Arakawa H, Oka H, Yoshinari T, Monden Y. Effect of genistein on topoisomerase activity and on the growth of [val 12] Ha-ras transformed NIH 3T3 cells. Biochem Biophys Res Commun 1998;157:183-189.

24. Fotsis T, Pepper M, Adlercreutz H, et al. Genistein, a dietaryderived inhibitor of in vitro angiogenesis. Proc Natl Acad Sci USA 1993;90:2690-2694.

25. Constantinou A, Humberman E. Genistein as an inducer of tumor cell differentiation: Possible mechanisms of action. Proc Soc Exp Biol Med 1995;208:109-115.

26. Davis J, Muqim N, Bhuiyan M, Kucuk P, Sarkar F. Inhibition of prostate specific antigen expression by genistein in prostate cancer cells. Int J Oncol 2000;16:10911097.

27. Onozawa M, Fukuda K, Ohtani M, Akaza H, Sugimura $T$ Wakabayashi K. Effects of soybean isoflavones on cell growth and apoptosis of the human prostatic cancer cell line LNCaP. Jpn J Clin Oncol 1998:28:360-363.

28. Killian C, Emrich L, Vargas F, et al. Relative reliability of five serially measured markers for prognosis of progression in prostate cancer. J Natl Cancer Inst 1986:76:179-185.

29. Seamonds B, Whitaker B, Yang N, Shaw L, Anderson K, Bollinger J. Evaluation of prostate-specific antigen and 
prostatic acid phosphatase as prostate cancer markers. Urology 1986;28:472-479.

30. Davis J, Kucuk O, Djuric Z, Sarkar F. Soy supplementation in healthy men inhibits NF- $\kappa B$ activation by TNF- $\alpha$ in blood lymphocytes. Free Radic Biol Med 2001;30:1293-1302.

31. Sadar M. Androgen independent induction of PSA gene expression via cross talk between AR and PKA signaling pathways. J Biol Chem 1999;274:7777-7783.

32. Yeh $S$, Lin $H$, Kang $H$, Thin $H$, Llin $M$, Chang C. From Her2/ neu signal cascade to androgen receptor and its coactivators: A novel pathway by induction of androgen target genes through MAP kinase in prostate cancer cells. Proc Natl Acad Sci USA 1999;96:5458-5463.

33. Craft N, Shostak $Y$, Carey M, Sawyers $C$. A mechanism for hormone-independent prostate cancer through modulation of androgen receptor signaling by the Her2/neu tyrosine kinase. Nature Med 1999;5:280-285.

34. Wang L, Liu X, Kreis W, Budman D. Phosphorylation/ dephosphorylation of androgen receptor as a determinant of androgen agonistic or antagonistic activity. Biochem Biophys Res Commun 1999;259:21-28.

35. Wang TT, Sathyamoorthy N, Phang JM. Molecular effects of genistein on estrogen receptor mediated pathways. Carcinogenesis 1996;17:271-275.

36. Zava D, Duwe G. Estrogenic and antiproliferative properties of genistein and other flavonoids in human breast cancer cells in vitro. Nutr Cancer 1997;27:31-40.

37. Culig Z, Hobisch A, Cronauer M. Mutant androgen receptor detected in an advanced-stage prostatic carcinoma is activated by adrenal androgens and progesterone. Mol Endocrinol 1993;7:1541-1550.

38. Noble RL. Prostate carcinoma of the Noble rat in relation to hormones. Int Rev Exp Pathol 1982;23:113-159.

39. Wang $Y$, Wong Y. Sex hormone-induced prostatic carcinogenesis in the Noble rat: The role of insulin-like growth factor-1 (IGF-1) and vascular endothelial growth factor (VEGF) in the development of prostate cancer. Prostate 1998;35:165-177.

40. Dahiya R, Park H, Cusick J, Vessella R, Fournier G, Narayan P. Inhibition of tumorigenic potential and prostate-specific antigen expression in LNCaP human prostate cancer cell line by 13-cis-retinoic acid. Int J Cancer 1994;59:126-132.
41. Hsieh T, Wu J. Effects of fenretinide (4-HPR) on prostate LNCaP cell growth, apoptosis and prostate-specific antigen expression. Prostate 1997;33:97-104.

42. Sun X, Plouzek C, Henry J, Wang T, Phang J. Increased UDPglucuronsyltransferase activity and decreased prostate specific antigen production by biochanin A in prostate cancer cells. Cancer Res 1998;58:2379-2384.

43. Xing N, Chen $Y$, Mitchell S, Young C. Quercetin inhibits the expression and function of the androgen receptor in $\mathrm{LNCaP}$ prostate cancer cells. Carcinogenesis 2001;22:409-414.

44. Gradin K, Whitelaw M, Toftgard R, Poellinger L, Berghard A A tyrosine kinase-dependent pathway regulates liganddependent activation of the dioxin receptor in human keratinocytes. J Biol Chem 1994;269:23800-23807.

45. Reinikainen P, Palvimo J, Janne O. Effects of mitogens on androgen receptor-mediated transactivation. Endocrinology 1996;137:4351-4357.

46. Miyamoto $H$, Yeh S, Wilding G, Chawnshang C. Promotion of agonist activity of antiandrogens by the androgen receptor coactivator, ARA70, in human prostate cancer DU145 cells. Proc Natl Acad Sci USA 1998;95:73797384.

47. Routledge E, White R, Parker M, Sumpter J. Differential effects of xenoestrogens on coativator recruitment by estrogen receptor (ER) $\alpha$ and ER $\beta$. J Biol Chem 2000;275: 35986-35993

48. An J, Tzagarakis-Foster C, Scharschmidt T, Lomir N, Leitman D. Estrogen receptor $\beta$-selective transcriptional activity and recruitment of coregulators by phytoestrogens. J Biol Chem 2001;276:17808-17814.

49. Lau K, LaSpina M, Long J, Ho S. Expression of estrogen receptor (ER)- $\alpha$ and ER- $\beta$ in normal and malignant prostatic epithelial cells: Regulation by methylation and involvement in growth regulation. Cancer Res 2000;60:31753182.

50. Leav I, Lau K, Adams J, et al. Comparative studies of the estrogen receptors $\beta$ and $\alpha$ and the androgen receptor in normal human prostate glands, dysplasia, and in primary and metastatic carcinoma. Am J Path 2001;159:79-92.

51. Zand RSR, Jenkins DJA, Diamandis EP. Genistein: A potent natural antiandrogen [Letter]. Clin Chem 2000;46:887888. 